\title{
Ataxia telangiectasia
}

\section{Ataxia telangiectasia}

\author{
Letícia Sauma, Karine C. S. Teixeira, Maria Augusta Montenegro
}

Ataxia-telangiectasia is an autosomal recessive disorder caused by mutation in the ATM gene. Symptoms are characterized by progressive cerebellar ataxia, dysarthria, oculomotor apraxia, chorea/dystonia, oculocutaneous telangiectasias, endocrine dysfunction, immunodeficiency, premature aging, radiosensitivity, and predisposition to cancer. Ataxia is evident in the first year of life, and results in wheelchair dependency for most children by age of 10 years-old. Laboratory tests show raised serum alpha-fetoprotein levels. Brain MRI shows cerebellar atrophy (Figure). It may also show multiple $\mathrm{T} 1$ and $\mathrm{T} 2$ hypointense foci suggestive of hemosiderin, probably related to thrombosis and vascular leaks from multiple capillary telangiectasias $^{1,2}$. There is no definitive treatment available ${ }^{3}$.
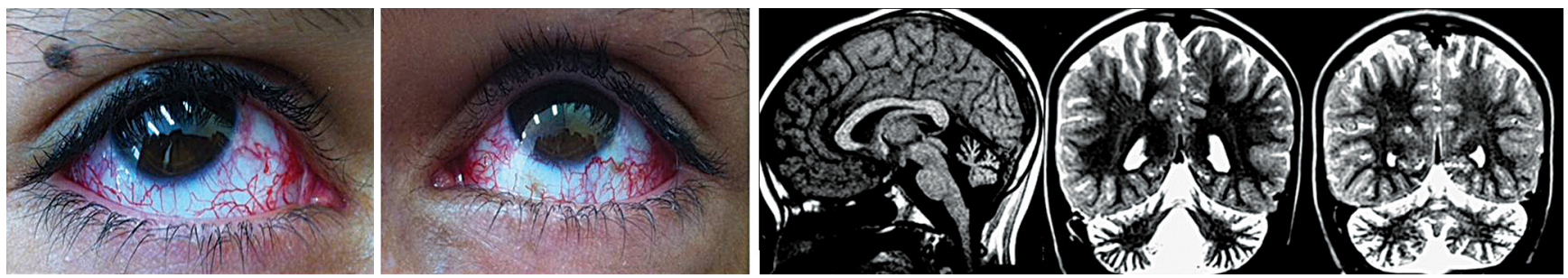

Figure. Nine year-old boy who presented gait difficulties since age two-years-old. Left figures: bilateral ocular telangiectasias. Right figures: MRI (sagittal T1 and coronal T2) images showing cerebellar atrophy.

\section{References}

1. Lin, DD, Barker PB, Lederman HM, Crawford TO. Cerebral abnormalities in adults with ataxia-telangiectasia. AJNR Am J Neurodadiol. 2014;35(1):119-23. http://dx.doi.org/10.3174/ajnr.A3646
2.

Sahama I, Sinclair K, Pannek K, Lavin M, Rose S. Radiological imaging in ataxia telangiectasia: a review. Cerebellum. 2014;13(4):521-30. http://dx.doi.org/10.1007/s12311-014-0557-4

3. Chaudhary MW, Al-Baradie RS. Ataxia-telangiectasia: future prospects. Appl Clin Genet. 2014;7:159-67. http://dx.doi.org/10.2147/TACG.S35759 